BMJ Open Sport \& Exercise Medicine

\title{
Sex differences in outcomes after arthroscopic bankart repair
}

\section{Natalie A Lowenstein (D), Peter J Ostergaard, Daniel B Haber, Kirsten D Garvey, Elizabeth G Matzkin}

To cite: Lowenstein NA, Ostergaard PJ, Haber DB, et al. Sex differences in outcomes after arthroscopic bankart repair. BMJ Open Sport \& Exercise Medicine 2020;6:e000965. doi:10.1136/ bmjsem-2020-000965

Accepted 17 December 2020

\section{ABSTRACT}

Objectives Risk factors for anterior shoulder dislocation include young age, contact activities and male sex. The influence of sex on patient-reported outcomes of arthroscopic Bankart repair (ABR) is unclear, with few studies reporting potential differences. This study's purpose was to compare patient-reported outcomes of males and females following ABR.

Methods Prospectively collected data was analysed for 281 patients (males: 206, females: 75) after ABR with preoperative, 1-year and 2-year follow-up responses. The Wilcoxon signed-rank and $\chi^{2}$ tests, preoperative, 1 year and 2 year follow-up results were examined to determine differences of scores in males versus females.

Results No statistically significant sex differences were observed in Simple Shoulder Test (SST), American Shoulder and Elbow Surgeons (ASES), Visual Analogue Scale (VAS) or Single Assessment Numerical Evaluation (SANE) Scores at 1-year or 2-year follow-up. Females had lower Veterans RAND 12-item health survey (VR-12) mental health subscores at 2-year follow-up (females: $52.3 \pm 9.0$, males: $55.8 \pm 7.6, p=0.0016)$. Females were more likely to report that treatment had 'exceeded expectations' at 2-year follow-up regarding motion, strength, function and normal sports activities.

Conclusion Results of study demonstrate that $A B R$ has similar outcomes for both males and females. There were no statistically significant sex-related differences in SST, ASES, VAS or SANE scores following ABR. VR-12 mental health subscores showed a minimal difference at 2-year follow-up, with lower scores in females.

Level of evidence Retrospective cohort study; level II.

\section{INTRODUCTION}

Anterior shoulder instability in the USA has a reported incidence of 23.9 per 100000 . Risk factors for primary dislocation include young age, participation in contact sports or activities, and male sex. Shoulder dislocations have a higher incidence and have resulted in longer return-to-play times than other shoulder injuries, especially at the level of high school and college athletics. ${ }^{1}$ Surgical intervention for anterior instability has increasingly consisted of an arthroscopic Bankart repair (ABR) in the absence of a glenoid bone loss exceeding $20 \%-25 \% .^{2}$ Results of ABR have shown similar

\section{What are the new findings?:}

Males and females had significantly improved American Shoulder and Elbow Surgeons, Simple Shoulder Test and Single Assessment Numerical Evaluation Scores following arthroscopic Bankart repair at 2-year follow-up.

- Females were more likely than males to report that treatment had 'met or exceeded expectations' at 2year follow-up regarding pain, motion, strength, resuming normal function for daily living and resuming normal sports activities.

- Females demonstrated lower Veterans RAND 12item health survey mental health scores at 2-year follow-up.

if not improved outcomes when compared with open Bankart repair. ${ }^{3}$

The influence of sex on the patientreported outcomes measures (PROMs) of ABR is unclear, and few studies have reported on these potential differences. Recent studies have shown an approximately 2.8 times higher incidence of shoulder dislocations in males compared with females, and that males under the age of 20 years have a 6.7 times greater risk of anterior shoulder dislocation requiring a closed reduction. ${ }^{45}$ Current literature fails to look at potential sex differences in both the management of anterior shoulder instability and the reliability of surgical treatment in both males and females. ${ }^{67}$ One non-operative study, with 27 females and 225 males, showed that at every time point following primary shoulder dislocation, the risk of recurrent instability was lower in females than in males. ${ }^{8}$ More recent literature contrarily, suggests that the rate of recurrent instability could be similar between sexes and risk factors for recurring subluxations are more often younger age and preoperative glenoid defect. ${ }^{910}$

The purpose of this study was to determine if there are sex-related differences in PROMs following ABR for anterior instability. The authors hypothesised that PROMs are similar in both males and females, and, therefore, ABR is a reliable treatment in both populations. 


\section{METHODS}

The authors performed a retrospective analysis of prospectively collected global data (Surgical Outcomes System Database) for patients who underwent ABR for shoulder instability between the years 2011 and 2016 . Two-hundred-and-eighty-one patients who had an arthroscopic anterior-inferior labral repair (CPT 29806) following at least one episode of anterior shoulder instability and had complete preoperative, 1-year and 2-year outcome data were included in the analysis. Patients and the public were not involved in the design, or conduct, or reporting, or dissemination plans of the research. Patients were included as participants in this research only. Approval for this study was obtained from our institutional review board (\#2011P002663).

Multiple validated measures were included within each time point of data collection to accurately capture pain levels, shoulder function and instability. For statistical analysis, the Wilcoxon signed-rank test and $\chi^{2}$ test, 1-year and 2-year follow-up results were examined to determine any differences in patient-reported outcomes in males versus females using the Visual Analogue Scale (VAS), Simple Shoulder Test (SST), Veterans RAND 12-item health survey (VR-12) physical health, VR-12 mental health, American Shoulder and Elbow Surgeons (ASES) Scores and the Single Assessment Numerical Evaluation (SANE) Scores. A p value $<0.05$ was used to determine statistically significant differences.

\section{RESULTS}

A total of 281 patients (206 male and 75 female) met the strict inclusion criteria and had complete preoperative, 1-year and 2-year follow-up data. Study demographics for these two groups are given in table 1.

Overall, both male and female patients had significantly improved ASES, SST and SANE Scores from preoperative to both 1-year and 2-year follow-up (table 2). There were no statistically significant differences observed in ASES, SST, SANE or VAS scores in females versus males at 1-year or 2-year follow-up (table 2). VR-12 mental and physical health scores showed some improvement from preoperative to 1-year follow-up and from preoperative to 2-year follow-up (table 2). There we no statistically significant differences between 1 year and 2years, postoperatively. Although the VR-12 physical health subscores did not show statistically significant differences between sex (53.3 \pm 5.7 in females vs $52.3 \pm 5.6$ in males; $\mathrm{p}=0.0951$ ),

Table 1 Demographic and surgical characteristics

\begin{tabular}{|c|c|c|}
\hline & Female & Male \\
\hline $\begin{array}{l}\text { Age at treatment (mean (SD)) } \\
\text { in years }\end{array}$ & $35.6(15.1)$ & $34.1(16.2)$ \\
\hline Sex & 75 & 206 \\
\hline Body Mass Index (mean (SD)) & $26.3(5.9)$ & $26.3(3.8)$ \\
\hline $\begin{array}{l}\text { Average duration of symptoms } \\
\text { (mean (SD)) in months }\end{array}$ & $42.1(78.7)$ & $33.0(65.2)$ \\
\hline
\end{tabular}

Table 2 Preoperative and 2-year postoperative ASES, SST, SANE, VAS and VR-12 physical and mental health scores by sex

\begin{tabular}{llll}
\hline & \multicolumn{2}{l}{ Sex } & \\
\cline { 2 - 3 } Outcome score & Female & Male & P value \\
\hline ASES Shoulder Function & & & \\
Preoperative & $17.4(6.1)$ & $18.2(6.1)$ & 0.3125 \\
\hline 2 year & $27.4(4.7)$ & $27.6(3.1)$ & 0.1626 \\
\hline ASES Shoulder Index & & & \\
\hline Preoperative & $61.1(19.2)$ & $64.4(19.5)$ & 0.2236 \\
\hline 2 year & $91.1(18.8)$ & $92.6(12.7)$ & 0.8153 \\
\hline SANE & & & \\
\hline Preoperative & $46.5(20.9)$ & $42.8(27.7)$ & 0.2012 \\
\hline 2 year & $82.9(23.5)$ & $83.7(20.7)$ & 0.7924 \\
\hline SST & & & \\
\hline Preoperative & $55.1(26.0)$ & $63.8(25.4)$ & 0.0314 \\
\hline 2 year & $91.1(18.8)$ & $92.6(12.7)$ & 0.8153 \\
\hline VAS & & & \\
\hline Preoperative & $3.6(2.6)$ & $3.2(2.6)$ & 0.2237 \\
\hline 2 year & $1.0(1.9)$ & $0.8(1.2)$ & 0.5846 \\
\hline VR-12 Physical Health & & & \\
\hline Preoperative & $40.3(6.8)$ & $41.0(8.5)$ & 0.4238 \\
\hline 2 year & $53.3(5.7)$ & $52.3(5.6)$ & 0.0951 \\
\hline VR-12 Mental Health & & & \\
\hline Preoperative & $52.7(9.7)$ & $53.9(9.5)$ & 0.4258 \\
\hline 2 year & $52.3(9.0)$ & $55.8(7.6)$ & 0.0016 \\
\hline & & & \\
\hline
\end{tabular}

ASES, American Shoulder and Elbow Surgeons; SANE, Single Assessment Numerical Evaluation; SST, Simple Shoulder Test; VAS, Visual Analogue Scale; VR-12, Veterans RAND 12-item health survey.

females had lower VR-12 mental health subscores than males at 2-year postoperative follow-up $(52.3 \pm 9.0$ in females vs $55.8 \pm 7.6$ in males; $\mathrm{p}=0.0016$ ).

Males and females had the same responses to preoperative expectations and 1-year and 2-year outcomes for their treatment for almost all sections. Females, however, were more likely than males to report that treatment had 'met or exceeded expectations' on 2-year follow-up regarding pain, motion and strength, resuming normal function for daily living and resuming normal sports activities (table 3 ).

\section{DISCUSSION}

Both male and female patients who underwent ABR for anterior shoulder instability had significant improvements in patient-reported outcomes and the treatment met or exceeded expectations for pain, motion, strength, daily function and return to sport. This finding supports previous studies that demonstrated that $\mathrm{ABR}$ is a reliable treatment in patients with discrete Bankart lesions. ${ }^{11}$ Both the males and females in this investigation had similar 2-year ASES, SANE, VAS, SST and VR-12 Scores 
Table 3 Two-year postoperative satisfaction with ABR

\begin{tabular}{|c|c|c|c|c|c|}
\hline \multirow[b]{2}{*}{ 2-year standard postoperative questions } & \multicolumn{4}{|l|}{ Sex } & \multirow[b]{2}{*}{ P value } \\
\hline & Female & & Male & & \\
\hline \multirow{3}{*}{$\begin{array}{l}\text { How well did the treatment meet your } \\
\text { expectations with regards to your pain } \\
\text { level? }\end{array}$} & Did not meet expectations & $3 \%$ & Did not meet expectations & $5 \%$ & 0.0626 \\
\hline & Met expectations & $40 \%$ & Met expectations & $55 \%$ & \\
\hline & Exceeded expectations & $57 \%$ & Exceeded expectations & $40 \%$ & \\
\hline \multirow{3}{*}{$\begin{array}{l}\text { How well did the treatment meet } \\
\text { your expectations with regards to an } \\
\text { improvement in motion and strength of } \\
\text { the affected joint? }\end{array}$} & Did not meet expectations & $4 \%$ & Did not meet expectations & $16 \%$ & 0.0074 \\
\hline & Met expectations & $36 \%$ & Met expectations & $56 \%$ & \\
\hline & Exceeded expectations & $60 \%$ & Exceeded expectations & $28 \%$ & \\
\hline \multirow{3}{*}{$\begin{array}{l}\text { How well did the treatment meet your } \\
\text { expectations with regards to you } \\
\text { resuming normal functions for daily } \\
\text { living? }\end{array}$} & Did not meet expectations & $4 \%$ & Did not meet expectations & $6 \%$ & 0.0390 \\
\hline & Met expectations & $45 \%$ & Met expectations & $61 \%$ & \\
\hline & Exceeded expectations & $51 \%$ & Exceeded expectations & $33 \%$ & \\
\hline \multirow{4}{*}{$\begin{array}{l}\text { How well did the treatment meet your } \\
\text { expectations with regard to resuming } \\
\text { normal sporting activities? }\end{array}$} & Did not meet expectations & $6.0 \%$ & Did not meet expectations & $11.4 \%$ & 0.0273 \\
\hline & Met expectations & $43.3 \%$ & Met expectations & $54.7 \%$ & \\
\hline & Exceeded expectations & $34.3 \%$ & Exceeded expectations & $27.4 \%$ & \\
\hline & N/A & $16.4 \%$ & $\mathrm{~N} / \mathrm{A}$ & $6.5 \%$ & \\
\hline
\end{tabular}

*N/A indicates, 'I am not involved in sports'.

$\mathrm{ABR}$, arthroscopic Bankart repair.

when compared with previous studies done on similar populations. ${ }^{612}$ When comparing results between sexes, this study demonstrates that there is a minimal difference in patient-reported outcomes when comparing female versus male patients treated with $\mathrm{ABR}$.

Although numerous studies on shoulder instability and ABR exist, few discuss potential sex-related differences in PROMs (table 4). Two studies (male: 77, female: $94)^{13}$ (male: 24, female: 12) ${ }^{14}$ attempted to investigate sex-related differences following arthroscopic shoulder stabilisation and found that females have increased instability postoperatively but only evaluated functional outcomes rather than PROMs. Another study (male: 110, female: 13) demonstrated that female sex is associated with lower rates of recurrent instability following ABR. ${ }^{15}$

In this study, the only difference in patient-reported outcomes at 1-year or 2-year follow-up between the cohorts was the VR-12 mental health subscores at 2-year

Table 4 Outcomes and sex differences following instability in the current literature

\begin{tabular}{|c|c|c|c|}
\hline Author/year & $\begin{array}{l}\text { \# of ABR patients } \\
\text { Male:female }\end{array}$ & Outcomes & Sex differences \\
\hline Largacha et al $(2006)^{17}$ & $\begin{array}{l}233 \\
167: 66\end{array}$ & SST and SF-36 & $\begin{array}{l}\text { Females with increased functional deficits on SST } \\
\text { and poorer comfort score on SF-36 }\end{array}$ \\
\hline Flinkkilä et al (2010) ${ }^{12}$ & $\begin{array}{l}182 \\
132: 50\end{array}$ & Recurrent instability & $\begin{array}{l}\text { Recurrent instability in 27/98 males and 6/43 } \\
\text { females }\end{array}$ \\
\hline Kaipel et al $(2010)^{14}$ & $\begin{array}{l}36 \\
24: 12\end{array}$ & Constant-Murley & $\begin{array}{l}\text { Females showed a significantly decreased } \\
\text { Constant-Murley score and more positive } \\
\text { postoperative apprehension }\end{array}$ \\
\hline Hovelius et al $(2011)^{18}$ & $\begin{array}{l}88 \\
68: 20\end{array}$ & WOSI, SSV and DASH & $\begin{array}{l}\text { Female shoulders trended towards worse scores. } \\
\text { The difference was significant only for the DASH } \\
\text { score }(p=0.009)\end{array}$ \\
\hline Blomquist et al (2012) ${ }^{19}$ & $\begin{array}{l}369 \\
\text { M:F not reported }\end{array}$ & WOSI & No discussion of sex differences \\
\hline Cameron et al $(2013)^{20}$ & $\begin{array}{l}714 \\
630: 84\end{array}$ & Recurrent instability & No discussion of sex differences \\
\hline Marshall et al $(2017)^{7}$ & $\begin{array}{l}173 \\
151: 22\end{array}$ & Recurrent instability & No discussion of sex differences \\
\hline Nakagawa et al $(2017)^{10}$ & $\begin{array}{l}123 \\
110: 13\end{array}$ & Recurrent instability & No discussion of sex differences \\
\hline
\end{tabular}

DASH, Disabilities of the Arm, Shoulder and Hand; SF-36, 36-Item Short Form Survey; SST, Simple Shoulder Test; SSV, Subjective Shoulder Value; WOSI, Western Ontario Shoulder Instability Index. 
follow-up, with females reporting significantly worse scores than males. The VR-12 compares a patient's valuation of their health-related quality of life with a standardised population of reference. ${ }^{16}$ The standardised population's mental and physical component scores have a mean of 50 and SD of $10 .{ }^{16}$ These scores allow for comparable sex-based evaluations of physical and mental health statuses. Although the differences between males and females in this study are not statistically significant, it is worth noting that the VR-12 mental health subscores in the female population decreased at 2-year follow-up when compared with both preoperative and 1-year follow-up scores. This was the only metric among all PROMs that showed an overall decrease in patient-reported scoring from preoperative values. Interestingly, females were more likely than males to report that the treatment had 'exceeded expectations' regarding motion and strength, resuming normal function for daily living, and returning to normal sporting activities at 2-year follow-up.

\section{LIMITATIONS}

This study has several limitations. First and foremost, this study is limited by loss to follow-up that exists in a retrospective review of prospectively collected global data. Although 281 patients are less than the $80 \%$ needed to minimise follow-up bias, global data were used to ensure a population of females $(27 \%)$ higher than most populations reported in similar studies $(7 \%-15 \%) .{ }^{3} 1011$ When using global data, poor compliance may be secondary to patients being entered in the system and never sent the PROMs or patients failing to complete them in their entirety. Other limitations of using a global database include heterogeneity in reporting and data collection. With the use of global data, information regarding recurrent instability, initial date and number of dislocations, hand dominance, glenohumeral dislocation and glenoid bone defect was unable to be collected for all patients in the study. Although this information would have provided a more in depth look at the severity of the instability, the sole purpose of this study was to note any sex differences in PROMs at 1 year and 2 years.

As is true in most patient-reported questionnaires, there is a degree of ambiguity in the number of patients who do not respond to specific questions. Persistent symptoms, however, are shown to be reported more accurately when collected via self-administered questionnaires, such as the ones used in this study. ${ }^{3}$ Specifically, this study has a high percentage of patients who reported either 'unknown' or did not identify the number of shoulder dislocations prior to surgery. This result is limiting in that multiple studies have shown that the number of dislocations prior to ABR may predict worse outcomes. ${ }^{7}$ Lastly, this study does not report on the rate of recurrent dislocations following ABR after 2 years. Given that episodes of recurrent instability greatly affect patient-reported outcomes, future studies would aim to look at outcomes beyond 2-year time points. Strengths of this study are the large number of females with complete outcome data at 2 years following ABR.

\section{CONCLUSION}

The results of this study demonstrate that $A B R$ is an effective treatment in both males and females following anterior shoulder instability. There were no statistically significant sex-related differences in SST, ASES, VAS or SANE scores when comparing female versus male patients treated with ABR. VR-12 mental health subscores showed a minimal difference at 2-year follow-up, with lower scores seen in the female population.

Correction notice This article has been corrected since it first published. The provenance and peer review statement has been included.

Contributors All authors had substantial contributions to the conception as well as design of the work. Each author contributed to acquisition, analysis, and interpretation of data for the work. Further each author contributed to the drafting, revision, and final approval of this manuscript and has agreed to be accountable for all aspects of the work.

Funding The authors have not declared a specific grant for this research from any funding agency in the public, commercial or not-for-profit sectors.

\section{Competing interests None declared.}

Patient and public involvement Patients and/or the public were involved in the design, or conduct, or reporting, or dissemination plans of this research. Refer to the Methods section for further details.

\section{Patient consent for publication Not required.}

Ethics approval This research study was reviewed by the Committee on Clinical Investigations and approved by the institutional review board.

Provenance and peer review Not commissioned; externally peer reviewed.

Open access This is an open access article distributed in accordance with the Creative Commons Attribution Non Commercial (CC BY-NC 4.0) license, which permits others to distribute, remix, adapt, build upon this work non-commercially, and license their derivative works on different terms, provided the original work is properly cited, appropriate credit is given, any changes made indicated, and the use is non-commercial. See: http://creativecommons.org/licenses/by-nc/4.0/.

\section{ORCID iDs}

Natalie A Lowenstein http://orcid.org/0000-0003-0083-9167

Elizabeth G Matzkin http://orcid.org/0000-0001-8592-7187

\section{REFERENCES}

1 Kraeutler MJ, Currie DW, Kerr ZY, et al. Epidemiology of shoulder dislocations in high school and collegiate athletics in the United States: 2004/2005 through 2013/2014. Sports Health 2018;10:85-91.

2 Boileau P, Villalba M, Héry J-Y, et al. Risk factors for recurrence of shoulder instability after arthroscopic Bankart repair. J Bone Joint Surg Am 2006;88:1755-63.

3 Hobby J, Griffin D, Dunbar M, et al. Is arthroscopic surgery for stabilisation of chronic shoulder instability as effective as open surgery? A systematic review and meta-analysis of 62 studies including 3044 arthroscopic operations. J Bone Joint Surg Br 2007;89:1188-96.

4 Leroux T, Wasserstein D, Veillette C, et al. Epidemiology of primary anterior shoulder dislocation requiring closed reduction in Ontario, Canada. Am J Sports Med 2014;42:442-50.

5 Zacchilli MA, Owens BD. Epidemiology of shoulder dislocations presenting to emergency departments in the United States. J Bone Joint Surg Am 2010;92:542-9.

6 Owens BD, Cameron KL, Peck KY, et al. Arthroscopic versus open stabilization for anterior shoulder Subluxations. Orthop J Sports Med 2015;3:232596711557108.

7 Marshall T, Vega J, Siqueira M, et al. Outcomes after arthroscopic Bankart repair: patients with first-time versus recurrent dislocations. Am J Sports Med 2017;45:1776-82.

8 Robinson CM, Howes J, Murdoch $\mathrm{H}$, et al. Functional outcome and risk of recurrent instability after primary traumatic anterior 
shoulder dislocation in young patients. J Bone Joint Surg Am 2006;88:2326-36.

9 Hovelius LK, Sandström BC, Rösmark DL, et al. Long-Term results with the Bankart and Bristow-Latarjet procedures: recurrent shoulder instability and arthropathy. J Shoulder Elbow Surg 2001;10:445-52.

10 Nakagawa S, Mae T, Sato S, et al. Risk factors for the postoperative recurrence of instability after arthroscopic Bankart repair in athletes. Orthop J Sports Med 2017;5:232596711772649.

11 Cole BJ, Warner JJ. Arthroscopic versus open Bankart repair for traumatic anterior shoulder instability. Clin Sports Med 2000;19:19-48.

12 Flinkkilä T, Hyvönen P, Ohtonen P, et al. Arthroscopic Bankart repair: results and risk factors of recurrence of instability. Knee Surg Sports Traumatol Arthrosc 2010;18:1752-8.

13 Brown GA, Tan JL, Kirkley A. The LAX shoulder in females. issues, answers, but many more questions. Clin Orthop Relat Res 2000;372:110-22.

14 Kaipel M, Reichetseder J, Schuetzenberger S, et al. Sex-Related outcome differences after arthroscopic shoulder stabilization. Orthopedics 2010;33. doi:10.3928/01477447-20100129-18
15 Shibata H, Gotoh M, Mitsui Y, et al. Risk factors for shoulder redislocation after arthroscopic Bankart repair. J Orthop Surg Res 2014;9:53.

16 Oak SR, Strnad GJ, Bena J, et al. Responsiveness comparison of the EQ-5D, PROMIS global health, and VR-12 questionnaires in knee arthroscopy. Orthop J Sports Med 2016;4:232596711667471.

17 Largacha M, Parsons IM, Campbell B, et al. Deficits in shoulder function and general health associated with sixteen common shoulder diagnoses: a study of 2674 patients. J Shoulder Elbow Surg 2006;15:30-9.

18 Hovelius L, Vikerfors O, Olofsson A, et al. Bristow-Latarjet and Bankart: a comparative study of shoulder stabilization in 185 shoulders during a seventeen-year follow-up. J Shoulder Elbow Surg 2011;20:1095-101.

19 Blomquist J, Solheim E, Liavaag S, et al. Shoulder instability surgery in Norway: the first report from a multicenter register, with 1-year follow-up. Acta Orthop 2012;83:165-70.

20 Cameron KL, Mountcastle SB, Nelson BJ, et al. History of shoulder instability and subsequent injury during four years of follow-up: a survival analysis. J Bone Joint Surg Am 2013;95:439-45. 